\title{
Index of Subjects
}

Acid-base balance, blood and urine, effect of dietary hyrochloric acid and calcined magnesite, grass-meal diet, sheep 233

Acid-base status, effect of dietary and intraruminal hydrochloric acid and intraruminal sodium bicarbonate, grass-meal diet, sheep 22 I

Acidosis, effect of dietary and intraruminal hydrochloric acid and intraruminal sodium bicarbonate, grass-meal diet, sheep $22 \mathrm{I}$

Acidosis, effect of dietary hydrochloric acid and calcined magnesite, grass-meal diet, sheep 233

Adipose tissue, fatty acid metabolism, effect of dietary copper deficiency, rat 105

Adrenals, histology, effect of sodium and dietary potassium, steer I

Age, effect on cyanocobalamin absorption, pig 469

Age, onset of obesity, effect on weight loss, man 201

Albumin, serum concentration, relationship to serum colloidal osmotic pressure, kwashiorkor, children 459

Alkaline phosphatase, activity, effect of different products of digestion, small intestinal mucosa, rat, rabbit, cat and hen 205

Amino acid see also Cysteine, Histidine, Hydroxyproline, Isoleucine, Methionine, Selenocystine, Selenomethionine, Tryptophan

Amino acids, availability, microbiological assay, protein quality of feeding-stuffs, collaborative study I 53

Amino acids, diets with complementary compositions, sequential feeding, nitrogen utilization and growth, chicken I I 3

Amino acids, effect of addition to poor-qualityprotein diet, growth rate, food conversion efficiency, chicks 363

Amino acids, plasma amino acid index, use for determining limiting amino acids in diet, sheep 375

Amino acids, plasma, effect of glucose infusion, pre- and postparturient ewes 375

Amino acids, plasma, effect of ingestion of amino acid mixture simulating casein, and a tryptic hydrolysate of casein, man 259

Animal model, vitamin $\mathrm{B}_{12}$ deficiency, fruit bat (Rousettus aegyptiacus) 397

Antimethogens, activity of pivalate and adipate esters of trichloroethanol, effect on metabolism of sheep rumen micro-organisms, persistance on foliar application to ryegrass 449

Antimethanogens, physical properties, in vitro tests of activity, rumen micro-organisms, sheep 429

Aorta, mineral composition, histopathological study, magnesium deficiency, horse foal 45
Ascorbic acid, association between dietary intake and 'risk' factors affecting diet, man 5 I 7

Ascorbic acid, fortification of cane sugar and common salt, effect on iron absorption, man I4I

Bacteria, rumen, lipid metabolism, effect of highfat diet, sheep 25

Barley, supplement to dried-grass diets, effect of processing on intake and digestibility of diet and rumen $\mathrm{pH}$, sheep 493

Bat (Rousettus aegyptiacus) 397

Behavioural tests, effect of previous undernourishment, rats $5 \mathrm{II}$

Biotin, deficiency, effect on liver and kidney, wheat-based diets, growing chickens and layers 83

Bone, mineral composition, histopathological study, magnesium deficiency, horse foal 45

Calcium, absorption and retention, effect of increasing dietary $\mathrm{Ca}$ and phosphorus, young and mature $\mathrm{Ca}$-deficient wether sheep 3 I I

Calcium, balance, effect of dietary hydrochloric acid and calcined magnesite, grass-meal diet, sheep 233

Calcium, deficiency, effect on $\mathrm{Ca}$ and phosphorus retention, young and mature wether sheep 3 I I

Calcium, dietary, effect on retention, excretion and tissue distribution of lead, rat $35 \mathrm{I}$

Calcium, intake, effect of school milk, primary schoolchildren, socio-economic study 9 I

Calcium, serum and tissue contents, magnesium deficiency, horse foals 45

Calorimetry, measurement of heat loss, effect of environmental temperature and level of feeding, growing pig 279

Casein, formation of bonds resistant to proteolytic enzymes, effect of heat and glucose 163

Casein, simulated amino acid mixture and tryptic hydrolysate, effect of ingestion on plasma amino acids, man 259

Cat 205

Cattle see also Steer

Chicken 83, I $_{3}, 325,339,363$

Child see also Man

Child see also Schoolchildren

Child 9I, 459

Cobalt, flow rate, digestive tract, effect of diet, sheep 73

Collagenase, cornea, effect of retinol deficiency, rat 297

Colloidal osmotic pressure, serum, relationship to serum albumin and globulin concentration, kwashiorkor, children 459

Common salt, fortification with iron and ascorbic acid, effect on $\mathrm{Fe}$ absorption, man I4I 
Copper, dietary deficiency, effect on fatty acid metabolism of liver microsomes and adipose tissue, rat, 105

Copper, flow rate, digestive tract, effect of diet, sheep 73

Copper, metabolism, effect of dietary sulphur source, $\mathrm{Cu}-$ molybdenum-S interrelationship, sheep 4 II

Copper, whole-body retention, effect of dietary phytate, rat 243

Cornea, collagenase and proteinase activity, effect of retinol deficiency, rat 297

Creatine, metabolism, effect of selenium deficiency, rat I I9

Critical temperature, estimation, growing pig 279

Cyanocobalamin, absorption and retention, significance of binder-protein, effect of age, suckling piglets 469

Cyanocobalamin, ${ }^{57} \mathrm{Co}-$ labelled, retention, organ distribution and whole-body content, fruit bat (Rousettus aegyptiacus) 397

Cysteine, availability, estimation by in vitro and in vivo methods, food products 175

Cysteine, dietary sulphur supplement, effect on copper and molybdenum metabolism, sheep 4II

Cysteine, participation in formation of bonds resistant to proteolytic enzymes, effect of heat and glucose, casein 163

Desaturase activity, liver microsomes, effect of dietary copper deficiency, rat 105

Diet, effect on flow of micronutrients, digestive tract, sheep 73

Diet, feeding frequency, fat metabolism, rat I 5

Diet, nutrient content, sampling and experimental error in estimation by 'duplicate analysis' method $39 \mathrm{I}$

Diet, physical form, chopped and pelleted, fresh and dried grass, effect on eating and rumination time, sheep 59

Diet, quality and physical form, chopped and pelleted, effect on portal blood flow, heat production and oxygen consumption, gut, fasted and fed sheep 125

Dietary survey, older people, nutrient intake, incidence of 'risk' factors affecting diet $5 \mathbf{1 7}$

Dietary survey, primary schoolchildren, contribution of school milk to nutrient intake 9 i

Digesta, flow rate, diurnal fluctuations, pig 267

Digestibility, amino acids, effect of heat damage and propionylation of proteins, faecal and ileal content analysis technique, chicks 339

Digestibility, dried-grass diet, effect of processedbarley-based supplements, sheep 493

Digestibility, grass-meal diet, effect of adding hydrochloric acid and calcined magnesite, sheep 233

Digestion, enzyme activity, interaction of different products of digestion, small intestine, rat, rabbit, cat and hen 205
Digestive tract, heat production and oxygen consumption, effect of chopped and pelleted diets, fasted and fed sheep 125

Dipeptidases, activity, effect of different products of digestion, small intestinal mucosa, rat, rabbit, cat and hen 205

Dried grass, intake and digestibility, effect of processed-barley-based supplements, rumen pH, sheep 493

Drinking-water, magnesium content, effect on serum and tissue mineral composition, $\mathrm{Mg}$ deficiency, horse foals 45

Energy, association between dietary intake and 'risk' factors affecting diet, man 517

Energy, deficiency, effect on fibres and nuclei of skeletal muscle, pig $42 \mathrm{I}$

Energy exchanges, eating and rumination, effect of grass diets, sheep 59

Enzyme see also Alkaline phosphatase, Collagenase, Desaturase, Dipeptidases, Glucoamylase, Proteinase, Transketolase

Enzyme, method for determination of available sulphur amino acids, food proteins 175

Enzymes, digestion, interaction of different productions of digestion, small intestinal mucosa, rat, rabbit, cat and hen 205

Enzyme activity, fatty acid metabolism, liver, effect of biotin deficiency, wheat-based diets, growing chickens and layers 83

Ewe see also Sheep

Faecal analysis, determination of amino acid digestibility, heat-damaged and propionylated proteins, chicks 339

Fat, dietary, effect on fat metabolism and deposition, feeding frequency, rat 15

Fat, metabolism, effect of dietary fat and feeding frequency, rat 15

Fat pads, lipogenesis rate, fatty acid composition, effect of dietary fat and feeding frequency, rat I5

Fatty acids, lipid metabolism, rumen microorganisms, effect of high-fat diet, sheep 25

Fatty acid composition, adipose tissue, effect of dietary copper deficiency, rat $\mathrm{O}_{5}$

Fatty acid composition, liver, effect of biotin deficiency, wheat-based diets, growing chickens and layers $8_{3}$

Feeding-stuffs, protein quality, availability of amino acids, microbiological assay $\mathbf{I} 33$

Fermentation, rumen, effect of high-fat diet, diet, sheep 25

Fish see Turbot 383

Fish meal, amino acid composition, effect of sequential feeding with sunflower meal, nitrogen utilization and growth, chicken I I 3

Fish meals, protein quality, available methionine, tryptophan and isoleucine, microbiological assay 153

Fistula-feeding, effect of grass diets on heat production, gut, sheep 59

Foal, see also Horse 
Folic acid, serum erythrocyte levels, effect of vitamin $B_{12}$ deficiency induced by all-fruit diet, fruit bat (Rousettus aegyptiacus) 397

Folic acid, tissue and milk content, capacity of binder-protein, effect of age, suckling piglet 469

Food, nutrient content, sampling and experimental errors in estimation by 'duplicate analysis' method 391

Food intake, cyclic pattern, effect of dietary phytate, rat 243

Food intake, effect of dietary and intraruminal hydrochloric acid and of intraruminal sodium bicarbonate, pelleted grass-meal diet, sheep $22 \mathrm{I}$

Food intake, effect of dietary hydrochloric acid and calcined magnesite, grass-meal diet, sheep 233

Foot lesions, biotin deficiency, effect of wheatbased diets, growing chickens and layers 83

Globulin, serum concentration, relationship to serum colloidal osmotic pressure, kwashiorkor, children 459

Glucoamylase, activity, effect of different products of digestion, small intestinal mucosa, rat, rabbit, cat and hen 205

Glucose, effect of infusion on plasma free amino acids, pre- and postparturient ewes 375

Glucose, effect on formation of bonds resistant to proteolytic enzymes, casein $16_{3}$

Glucose, intestinal absorption, diurnal fluctations, pig 267

$\epsilon$ - $(\gamma$-L-glutamyl)-L-lysine, metabolism, rat $29 \mathrm{I}$

Grass diet, fresh or dried, pelleted or chopped, effect on eating and rumination times and energy exchanges, sheep 59

Grass-meal diet, effect of hydrochloric acid on food intake and on metabolism, sheep 221

Groundnut meal, low-quality dietary protein source, effect on growth rate and food conversion efficiency, chicks 363

Growth rate, effect of dietary phytate, rat 243

Heat, effect on formation of bonds resistant to proteolytic enzymes, casein 163

Heat damage, effect on nutritional value of proteins as sources of lysine, methionine and tryptophan, chemical, microbiological and biological assays 325

Heat damage, proteins, effect on digestibility of amino acids, faecal and ileal content analysis techniques, chicks 339

Heat increment of feeding, effect of chopped and pelleted diets, sheep 125

Heat loss, effect of fasting, environmental temperature and level of feeding, growing pig 279

Heat of fermentation, gut, effect of chopped and pelleted diets, fasted and fed sheep 125

Heat production, eating and rumination, effect of fresh- and dried-grass diets, sheep 59

Heat production, gut, effect of chopped and pelleted diets, sheep 125
Hen 205

Herring meal, dietary protein source, effect on growth rate and food conversion efficiency, chicks 363

Histidine, intestinal absorption, diurnal fluctuation, pig 267

Horse 45

Hydrochloric acid, effect of addition to diet and intraruminal infusion with or without intraruminal sodium bicarbonate, food intake, acidosis, sheep $22 \mathrm{I}$

Hydroxyproline, cornea, effect of retinol deficiency, rat 297.

Ileal content analysis, determination of amino acid digestibility, heat-damaged and propionylated proteins, chicks 339

Inhibitors, antimethanogens, physical properties, in vitro tests with sheep rumen micro-organisms 429

Intestine, absorption of glutamyl-lysine in vitro and in vivo, rat $29 \mathrm{I}$

Intestine, absorption of histidine and glucose, diurnal fluctuations, pig 267

Intestine, zinc absorption and secretion, effect of dietary phytate, rat $\mathbf{2 4 3}$

Intrinsic factor, effect on cyanocobalamin absorption, effect of age, suckling piglet 469

Iron, absorption, effect of using fortified cane sugar and common salt, man $14 \mathrm{r}$

Iron, whole-body retention, effect of dietary phytate, rat 243

Isoleucine, availability, microbiological assay, protein quality, fish meals, collaborative study I 53

Kidney, vitamin $\mathbf{B}_{12}$ concentration, effect of allfruit diet on retention of $\left[{ }^{57} \mathrm{Co}\right]$ cyanocobalamin, fruit bat (Rousettus aegyptiacus) 397

Kwashiorkor, relationship between serum colloidal osmotic pressure and albumin and globulin concentrations, children 459

Magnesium, balance, effect of dietary hydrochloric acid and calcined magnesite, grass-meal diet, sheep 233

Magnesium, dietary deficiency, serum and tissue Mg, calcium and phosphorus, histopathological study, horse foal 45

Man see also Child

Man 9I, I4I, 20I, 259, 459, 5 I 7

Manganese, flow rate, digestive tract, effect of diet, sheep 83

Manganese, whole-body retention, effect of dietary phytate, rat $\mathbf{2 4 3}$

Meal-feeding, effect on fat metabolism and deposition, rat is

Methane, in vitro production by sheep rumen micro-organisms, activity of new antimethogens 429

Methane, production by sheep rumen microorganisms, antimethogenic activity of pivalate and adipate esters of trichloroethanol 447 
Methionine, availability, effect of heat damage and propionylation of proteins, chick growth assay 325

Methionine, availability, estimation by in vitro and in vivo methods, food products 175

Methionine, availability, microbiological assay, protein quality, fish meals, collaborative study I 53

Methionine, dietary sulphur supplement, effect on copper and molybdenum metabolism, sheep 4 II

Methionine, limiting amino acid, effect of addition to low-quality-protein diets, growth rate, food conversion efficiency, chicks $36_{3}$

Methionine, participation in formation of bonds resistant to proteolytic enzymes, effect of heat and glucose, casein 163

Micro-organisms, rumen, lipid metabolism, effect of high-fat diet, sheep 25

Microsomes, liver, desaturase activity, effect of dietary copper deficiency, rat 105

Milk see also School milk

Milk, significance of binder-proteins, cyanocobalamin and folate absorption and retention, suckling piglet 469

Minerals see also Calcium, Cobalt, Copper, Iron, Magnesium, Manganese, Molybdenum, Potassium, Phosphorus, Selenium, Sulphur, Zinc

Molybdenum, metabolism, effect of dietary sulphur source, copper-Mo-S interrelationship, sheep 4II

Muscle, creatine metabolism, effect of dietary selenium deficiency, rat 1 I 9

Muscle, $m$. flexor digiti $\mathrm{V}$ brevis, fibres and nuclei, effect of nutritional status, pig $42 \mathrm{I}$

Muscular dystrophy, nutritional, creatine metabolism, effect of selenium deficiency, rat I I 9

Nibbling, effect on fat metabolism and deposition, rat, 15

Nitrogen, utilization, effect of sequential feeding with sunflower meal and fish meal, growth, chicken $I x 3$

Nutrient content, food, sampling and experimental errors in estimation by 'duplicate analysis' method 391

Nutrient intake, association with 'risk' factosr affecting diet, man 517

Nutrient intake, calcium and riboflavin status, effect of school milk, primary schoolchildren, socio-economic study $9 \mathrm{I}$

Nutritional status, primary schoolchildren, effect of school milk, socio-economic study $9 \mathrm{I}$

Obesity, effect of age of onset, weight loss, man $20 \mathrm{I}$

Palatability, grass-meal diet, effect of dietary hydrochloric acid, sheep 221

Parotid salivary gland, histology, effect of sodium and dietary potassium, steer I

Perennial ryegrass, effect on flow of micronutrients, digestive tract, sheep 73

$\mathrm{pH}$, rumen, effect of processed-barley-based supplements, dried-grass diet, sheep 493
Phosphorus, absorption and retention, effect of increasing dietary calcium and $P$, young and mature Ca-deficient wether sheep 3 I I

Phosphorus, dietary, effect on retention, excretion and tissue distribution of lead, rat $35 \mathrm{I}$

Phosphorus, serum and tissue content, effect of magnesium deficiency, horse foal 45

Phytate, dietary, effect on intestinal absorption and secretion of zinc, retention of $\mathrm{Zn}$, copper, iron and manganese, rat 243

Pig 267, 279, 421, 469

Piglet see also Pig

Portal blood flow, effect of chopped and pelleted diets, fasted and fed sheep 125

Potassium, effect on sodium requirement, bodyfluid composition, adrenal and parotid salivary gland histology, steer I

Potato, mashed and boiled, nutrient content, sampling and experimental errors in estimation by 'duplicate analysis' method 391

Pregnancy, plasma free amino acids, effect of glucose infusion, ewes 375

Propionylation, effect on nutritional value of proteins, chemical, biological and microbiological assays 325

Propionylation, proteins, effect on digestibility of amino acids, faecal and ileal content analysis techniques, chicks 339

Protein, casein, simulated amino acid mixture and tryptic hydrolysate, effect on plasma amino acids, man 259

Protein, food products, effects of processing on available sulphur amino acid content I75

Protein, formation of bonds resistant to proteolytic enzymes, effects of heat and glucose I 63

Proteins, propionylated and heat-damaged, digestibility of amino acids, chick assay 339

Protein(s), heat-damaged and propionylated, nutritional value, determined by chemical, microbiological and biological assays 325

Protein deficiency, effect on fibres and nuclei of skeletal muscle, pig $42 \mathrm{I}$

Protein quality, effect on growth rate, food conversion efficiency, chicks $36_{3}$

Protein quality, feeding-stuffs, available amino acids, microbiological assay, collaborative study 153

Proteinase, activity, cornea, effect of retinol deficiency, rat 297

Protozoa, rumen, lipid metabolism, effect of highfat diet, sheep 25

Pyrithiamin, thiamin antagonist, effect of addition to diet, growth, turbot (Scophthalmus maximus) $3^{8} 3$

Rabbit 205

Rat 15, 105, II9, 175, 205, 243, 29I, 297, 35I, 5OI, 5 I I

Retinol, deficiency, effect on collagenase and proteinase activity, cornea, rat 297

Riboflavin, intake, effect of school milk, primary schoolchildren, socio-economic study $9 \mathrm{I}$ 
Rumen, antimethanogenic activity of pivalate and adipate esters of trichlorethanol, metabolism of micro-organisms, sheep 447

Rumen, dilution rate, volume of contents, volatile fatty acids, micro-organisms, effect of high-fat diet, sheep, 25

Rumen, fermentation, volatile fatty acids, effect of dietary hydrochloric acid and calcined magnesite, grass-meal diet, sheep 233

Rumen, metabolism, effect of dietary and intraruminal hydrochloric acid and intraruminal sodium bicarbonate, grass-meal diet, sheep $22 \mathrm{I}$

Rumen, methane production, in vitro tests of new antimethanogens, sheep 429

Rumination time, effect of grass diets, sheep 59

Ryegrass, foliar application of trichloroethyl adipate, in vitro antimethanogenic activity of ryegrass extracts, sheep rumen micro-organisms 447

Schoolchildren 9 I

School milk, effect on nutrient intake and calcium and riboflavin status, primary schoolchildren, socio-economic study 9 I

Selenium, deficiency, effect on creatine metabolism, rat i 9

Selenium, metabolism of $\left[{ }^{75} \mathrm{Se}\right]$ selenocystine and ${ }^{75}$ Se]selenomethionine, rat $50 \mathrm{I}$

Selenocystine, ${ }^{75}$ Se-labelled, metabolism, rat $50 \mathrm{I}$

Selenomethionine, ${ }^{75} \mathrm{Se}$-labelled, metabolism, rat 501

Sheep 25, 59, 73, 125, 221, 233, 311, 375, 41 I, 429, 447, 493

Silage, effect of hydrochloric acid on intake, sheep 22 I

Small intestine, enzyme activity, interactions of products of digestion, rat, rabbit, cat and hen 205

Sodium, requirement, effect of dietary potassium, steer I

Sodium bicarbonate, intraruminal infusion, hydrochloric-acid-supplemented, grass-meal diet, effect on food intake and metabolism, sheep $22 \mathrm{I}$

Soya-bean meal, low-quality dietary protein source, effect on growth rate and food conversion efficiency, chicks $3^{6} 3$

Steer I

Streptococcus zymogenes assay, available amino acids, protein quality of feeding-stuffs, collaborative study 153

Sulphur, dietary, inorganic and organic, effects on copper and molybdenum metabolism, sheep $4 \mathrm{II}$

Sunflower meal, amino acid composition, effect of sequential feeding with fish meal, nitrogen utilization and growth, chicken I I3
Temperature, environmental, effect on heat loss at different levels of feeding, growing pig 279

Thiamin, estimation of requirement, turbot (Scophthalmus maximus) 383

Transketolase, erythrocyte activity, effect of dietary thiamin, turbot (Scophthalmus maximus) 383

Trichloroethyl adipate, antimethanogenic activity in vivo, sheep 447

Trichloroethyl adipate, physical properties, antiantimethanogenic activity in vitro, sheep 429

Trichloroethyl pivalate, antimethanogenic activity in vivo, sheep 447

Trichloroethyl pivalate, physical properties, methanogenic activity in vitro, sheep 429

Tryptophan, availability, effect of heat damage and propionylation of protein, chick growth assay $\mathbf{3 2 5}$

Tryptophan, availability, microbiological assay, protein quality of fish meals, collaborative study I 53

Turbot (Scophthalmus maximus) 383

Undernourishment, effect on response in behavioutal tests, tat 5 II

Vitamin(s) see also Ascorbic acid, Biotin, Cyanocobalamin, Folic acid, Retinol, Riboflavin, Thiamin

Vitamin $B_{12}$, organ distribution and biological half-life, effect of deficiency induced by all-fruit diet, folate metabolism, fruit bat (Rousettus aegyptiacus) 397

Vitamin D, association between intake and 'risk' factors affecting diet, man $5 \mathrm{I} 7$

Vitamin E, content of sorghum grain, effect on sodium requirements and growth, steer I

Volatile fatty acids, production by rumen micro-organisms, effect of high-fat diet, sheep 25

Volatile fatty acids, rumen, effect of dietary and intraruminal hydrochloric acid and intraruminal sodium bicarbonate, grass-meal diet, sheep $22 \mathrm{I}$

Volatile fatty acids, rumen, effect of dietary hydrochloric acid and calcined magnesite, grassmeal diet, sheep 233

Weight loss, effect of age of onset of obesity, man 201

Zinc, flow rate, digestive tract, effect of diet, sheep 73

Zinc, intestinal absorption and secretion, wholebody retention, effect of dietary phytate, rat 243 